\title{
Strategies for spinal surgery reimbursement: bundling in the working- age population
}

\author{
Michael K. Dalton 1* (D), Christer Mjåset ${ }^{2,3,4}$, Adoma Manful', Melvin D. Helgeson ${ }^{5}$, William Wynn-Jones ${ }^{1,4}$, \\ Zara Cooper ${ }^{1}$, Tracey P. Koehlmoos ${ }^{6}$ and Joel S. Weissman ${ }^{1}$
}

\begin{abstract}
Introduction: Bundled payments for spine surgery, which is known for having high overall cost with wide variation, have been previously studied in older adults. However, there has been limited work examining bundled payments in working-age patients. We sought to identify the variation in the cost of spine surgery among working age adults in a large, national insurance claims database.

Methods: We queried the TRICARE claims database for all patients, aged 18-64, undergoing cervical and noncervical spinal fusion surgery between 2012 and 2014. We calculated the case mix adjusted, price standardized payments for all aspects of care during the 60-, 90-, and 180-day periods post operation. Variation was assessed by stratifying Hospital Referral Regions into quintiles.

Results: After adjusting for case mix, there was significant variation in the cost of both cervical $(\$ 10,538.23,60 \%$ of first quintile) and non-cervical $(\$ 20,155.59,74 \%)$. Relative variation in total cost decreased from 60 - to 180 -days $(63$ to $55 \%$ and 76 to $69 \%$ ). Index hospitalization was the primary driver of costs and variation for both cervical (1st-to5th quintile range: $\$ 11,033-\$ 19,960)$ and non-cervical $(\$ 18,565-\$ 36,844)$ followed by readmissions for cervical $(\$ 0-\$ 11,521)$ and non-cervical $(\$ 0-\$ 13,932)$. Even at the highest quintile, post-acute care remained the lowest contribution to overall cost ( $\$ 2070 \& \$ 2984)$.

Conclusions: There is wide variation in the cost of spine surgery across the United States for working age adults, driven largely by index procedure and readmissions costs. Our findings suggest that implementing episodes longer than the current 90-day standard would do little to better control cost variation.
\end{abstract}

Keywords: Spine surgery, Bundled payments, Episode of care, Payment reform

\section{Introduction}

The United States (US) has long had the most expensive healthcare system per capita and healthcare expenditures continue to rise, without a demonstrable corresponding improvement in health outcomes [1, 2]. Among the

\footnotetext{
* Correspondence: mdalton9@bwh.harvard.edu

${ }^{1}$ Center for Surgery and Public Health, Harvard Medical School, Harvard T. H. Chan School of Public Health, Department of Surgery, Brigham and Women's Hospital, 1620 Tremont Street, 1 Brigham Circle, Boston, MA 02120, USA Full list of author information is available at the end of the article
}

recognized drivers of the ballooning healthcare costs are fragmentation of care, variation in costs at regional and provider level and variation in clinical practice [1]. In order to control the ever increasing amount spent on healthcare, several value based payment models have been proposed, one such model was bundled payments $[3,4]$.

Bundled payment models, such as the Centers for Medicare and Medicaid Services (CMS) Bundled Payments for Care Improvement (BCPI), offer a standardized payment

(C) The Author(s). 2021 Open Access This article is licensed under a Creative Commons Attribution 4.0 International License, which permits use, sharing, adaptation, distribution and reproduction in any medium or format, as long as you give appropriate credit to the original author(s) and the source, provide a link to the Creative Commons licence, and indicate if changes were made. The images or other third party material in this article are included in the article's Creative Commons licence, unless indicated otherwise in a credit line to the material. If material is not included in the article's Creative Commons licence and your intended use is not permitted by statutory regulation or exceeds the permitted use, you will need to obtain permission directly from the copyright holder. To view a copy of this licence, visit http://creativecommons.org/licenses/by/4.0/ The Creative Commons Public Domain Dedication waiver (http://creativecommons.org/publicdomain/zero/1.0/) applies to the data made available in this article, unless otherwise stated in a credit line to the data. 
for all healthcare provided during a defined time period, termed an "episode of care" [5]. Surgical care has been a prime target for bundled payments, due to variable costs though all phases of care and an easy to identify start date $[6,7]$. Several studies have shown that surgical bundles in Medicare have led to real or potential cost savings with no decrease in quality [8-13], including bundles for spine surgery [14]. Recent work by Wynn-Jones, et al., examined the potential impact of a bundled payment model on the cost of common surgical procedures among a working age adult population (age 18-64) including spinal surgery [15]. They found significant variation in overall costs and that spending patterns in the different phases of care for working age adults (including index hospitalization, readmissions, post-acute care, and physician fees) diverged from those observed in the older adult Medicare population.

Spine disorders are associated with high healthcare spending across the adult age spectrum in the US, making them a particularly attractive target for value based payment strategies, with one study finding that those with spine conditions had healthcare expenditures 73\% higher than those without spine disorders [16]. Other work utilizing national secondary data has shown that more than 400,000 primary spinal fusion operations are performed annually in the US and that the number of spine operations performed annually has been consistently increasing, with approximately half of patients requiring these operations under age 65 [17-19].

Prior studies of bundled payment models in spine surgery have largely examined the 65 -and-over Medicare population and focused on fixed 90-day episodes of care [14]. In our study, we evaluated variation in costs for spinal fusion surgery among working age adults to show the potential impact of implementing bundled payments in this population and identify drivers of variation in the cost of spine surgery. We also sought to identify variation in cost by indication for the procedure and to establish the optimal episode of care time period for spine surgery.

\section{Methods}

\section{Study data and population}

We employed data from the TRICARE claims in the Military Health System Data Repository. TRICARE is the US Department of Defense health insurance product that covers members of the armed forces, retirees, and their dependents; approximately $80 \%$ are not active duty servicemembers [20]. The population covered by TRIC ARE has been shown to be nationally and demographically representative of US population under 65 years of age [20, 21]. The US Military Health System (MHS) is a bifurcated care system, providing care at both military owned hospitals (direct care) and at civilian hospitals where TRICARE functions as a fee-for-service health insurance product (purchased care). Importantly, this system does not include care provided by the US Department of Veterans Affairs. This study examined data from TRICARE Prime, one of TRICARE's constituent insurance plans.

Patients who underwent spinal fusion operations between 2012 and 2014 were identified by International Classification of Diseases ICD, Ninth Revision, Clinical Modification (ICD-9-CM) Procedure Codes and Medicare Severity-Diagnosis Related Group (MS-DRG) Codes. Patients were stratified by procedure category: cervical spinal fusion and non-cervical spinal fusion (Additional file 1). Procedures performed for trauma, fracture, or malignancy were excluded. Demographic information, including age, sex, race, and the sponsor beneficiary's military rank, was collected. Sponsor rank has been previously used as a proxy for socio-economic status, with junior enlisted sponsor rank being considered indicative of lower socioeconomic status [22, 23]. For patients with missing data regarding race, their sponsor beneficiary's race was used.

In order to maximize our ability to capture all costs, patients with dual coverage with another payer were excluded. Patients who were admitted directly from skilled nursing, rehabilitation, or hospice facilities or who died during the index hospitalization were excluded in order to create a more homogenous cohort where we could focus on regional cost variation. As in prior studies, we used Hospital Referral Regions (HRR) as our aggregated unit of analysis $[15,24]$. HRRs where fewer than 5 cases were performed were excluded from this analysis.

\section{Calculation of Tricare payments}

We used payments made by TRICARE on behalf of each patient to commercial healthcare providers rather than submitted charges by the hospitals. We collected information on all payments made on behalf of each patient during the bundle period, including those for inpatient and outpatient services. We calculated payments made for all claims during episodes of care of varying duration (60-, 90-, and 180-day). All patient specific payment information for the 6 months prior to the index admission was used in calculation of the case mix index.

We applied a regional price standardization, similar to those used in Medicare, to control for claims cost variation resulting from variation in wage indices $[25,26]$. Factors included in case mix adjustment were patients' age, sex, race, sponsor rank, and admission acuity. We also included each patient's Charlson Comorbidity Index to account for pre-existing comorbid conditions and TRICARE claims payments made in the 6 months prior to the index procedure. 
Each payment was categorized into one of four payment buckets. The Index Hospitalization includes claims paid by TRICARE for the reference inpatient procedure. Readmission payments include claims paid for inpatient acute-care hospitalizations and procedures performed after discharge from the index hospitalization but within the bundle period. Post-acute care payments included those for acute or sub-acute rehabilitation facilities, skilled nursing facilities, outpatient services, home healthcare, hospice, durable medical equipment, as well as facility fees for outpatient care. Healthcare Professional Fees constituted the fourth category.

\section{Statistical methods}

Case mix adjustment was done using a generalized linear mixed model using a log link function. We included a random effect for the grouping variable HRR, to account for correlation of outcomes within an HRR, and assumed a gamma distribution based on prior literature on modelling cost data. From this, we obtained a case-mix and empirical Bayes reliability-adjusted estimate of the mean cost for each HRR. HRRs were sorted by the adjusted total payments made for the period from discharge from index hospitalization to the end of the episode of care duration. The payments were grouped into quintiles and the average per quintile reported with confidence intervals. Consistent with previous work, inter-quintile variation was measured by using the inter-quintile difference, defined as the absolute difference in dollars between the lowest and highest quintile, expressed as a percentage of the lowest quintile [15]. The HRRs were then resorted, grouped into quintiles and averaged, for each of the four payment buckets identified (i.e., Index Hospitalization payments, Readmission payments, Post-acute Care payments, and Healthcare Professional fees). This process was repeated each spinal fusion type and episode of care duration combination. (i.e., cervical vs noncervical at 60-, 90-, and 180-days).

Finally, we also followed each patient for 1 year after their index procedure to identify patients undergoing reoperation beyond what was captured by the 180-day bundle episode. This was done in order to test whether our longest episode duration (180-days) was sufficient to capture major sources of cost variation related to the index procedure in this population, or if delayed reoperations would mandate even longer episode durations to properly account for cost variability.

A $p$-value less than 0.05 was a priori determined to be statistically significant. All analyses were performed using SAS version 9.4. The study data were used under a data use agreement with the Uniformed Services University of the Health Sciences, and the study was deemed exempt from full review by the institutional review board of Uniformed Services University of the Health Sciences and the Partners Healthcare Human Research Committee.

\section{Results}

We identified 12,811 patients meeting inclusion criteria, of which 6977 underwent a cervical spine fusion and 5834 underwent a non-cervical spinal fusion. These procedures were performed for TRICARE beneficiaries in 168 HRRs during the study period and were included in this analysis.

Total costs for non-cervical spinal operations were higher than total costs for cervical spine operations (Table 1). There was significant variation in the price standardized and case mix adjusted (fully adjusted) amount paid by TRICARE for both cervical and noncervical spinal fusions. The inter-quintile variation in the fully adjusted price for non-cervical spinal fusions was higher than for cervical spinal fusions across 60 - (76\% vs $63 \%), 90$ - (74\% vs. $60 \%$ ), and 180 -day (69\% vs $55 \%)$ episodes, although the difference narrowed with increasing episode duration.

The index hospitalization contributed the most to the overall cost of both cervical and non-cervical spinal operations (Table 2). At 90 days, readmissions did not contribute to the overall cost in the lowest quintiles for both types of operation and therefore had large variation. Post-acute care costs had the smallest contribution to the overall costs for both types of operation (3\% in quintile 1 to $10 \%$ in quintile 5 ).

A total of $787(6.1 \%)$ patients underwent reoperation within 1 year of their index operation, of whom 357 (45.4\%) had their first reoperation within 180-days of their index operation. There were 386 cervical patients that underwent reoperation and 401 non-cervical. The mean time to first reoperation was 187 days (SD 109 days). A very small number $(39 ; 0.30 \%)$ of patients underwent multiple reoperations within 1 year.

\section{Discussion}

In this study, we examined costs of variable length episodes for working patients undergoing spine surgery for in a working-age adult population across the United States and found significant variation in the cost of both cervical and non-cervical spine surgery. However, even though overall costs and the absolute inter-quintile difference increased as the episode duration increased, the relative inter-quintile variation decreased. We also demonstrated that for this younger population, the postacute care spending component is only a small portion of the total spent during an episode of care, leading to relatively flat accumulation of costs in varying episode durations compared to the older adult populations.

As episode-based payment systems have evolved for patients over 65 insured by Medicare, interest has grown about the application to younger patients. Large companies, who are significant purchasers of healthcare in the US, are beginning to negotiate prospective bundled 
Table 1 Actual, price-standardized, and fully adjusted TRICARE payments during 60-, 90- and 180-day episode lengths for cervical and non-cervical spinal fusion

\begin{tabular}{|c|c|c|c|c|c|c|c|c|}
\hline \multirow[t]{2}{*}{ DRG } & \multirow{2}{*}{$\begin{array}{l}\text { Length of } \\
\text { Bundle }\end{array}$} & \multirow[t]{2}{*}{ Method of Cost Calculation } & \multicolumn{5}{|l|}{ Quintile } & \multirow{2}{*}{$\begin{array}{l}\text { Difference* } \\
\text { (\% of 1st } \\
\text { Quintile) }\end{array}$} \\
\hline & & & 1 & 2 & 3 & 4 & 5 & \\
\hline \multirow[t]{9}{*}{ Cervical } & \multirow[t]{3}{*}{60 day bundle } & Actual & $\$ 16,012$ & $\$ 17,760$ & $\$ 19,118$ & $\$ 21,512$ & $\$ 29,136$ & $\$ 13,124(82 \%)$ \\
\hline & & Price-Standardized & $\$ 16,671$ & $\$ 18,084$ & $\$ 19,203$ & $\$ 21,341$ & $\$ 27,562$ & $\$ 10,891(65 \%)$ \\
\hline & & Price Standardized + Casemix Adjusted & $\$ 16,728$ & $\$ 18,059$ & $\$ 19,112$ & $\$ 21,236$ & $\$ 27,281$ & $\$ 10,553(63 \%)$ \\
\hline & \multirow[t]{3}{*}{90 day bundle } & Actual & $\$ 16,677$ & $\$ 18,472$ & $\$ 19,929$ & $\$ 22,420$ & $\$ 30,259$ & $\$ 13,581(81 \%)$ \\
\hline & & Price-Standardized & $\$ 17,389$ & $\$ 18,865$ & $\$ 20,061$ & $\$ 22,166$ & $\$ 28,532$ & $\$ 11,143(64 \%)$ \\
\hline & & Price Standardized + Casemix Adjusted & $\$ 17,459$ & $\$ 18,804$ & $\$ 19,960$ & $\$ 22,077$ & $\$ 27,997$ & $\$ 10,538(60 \%)$ \\
\hline & \multirow[t]{3}{*}{180 day bundle } & Actual & $\$ 18,575$ & $\$ 20,560$ & $\$ 22,426$ & $\$ 24,884$ & $\$ 33,528$ & $\$ 14,953(81 \%)$ \\
\hline & & Price-Standardized & $\$ 19,483$ & $\$ 20,949$ & $\$ 22,616$ & $\$ 24,550$ & $\$ 31,129$ & $\$ 11,646(60 \%)$ \\
\hline & & Price Standardized + Casemix Adjusted & $\$ 19,570$ & $\$ 20,880$ & $\$ 22,309$ & $\$ 24,377$ & $\$ 30,261$ & $\$ 10,691(55 \%)$ \\
\hline \multirow[t]{9}{*}{ Non-cervical } & \multirow[t]{3}{*}{60 day bundle } & Actual & $\$ 25,879$ & $\$ 29,324$ & $\$ 32,028$ & $\$ 35,551$ & $\$ 49,211$ & $\$ 23,331(90 \%)$ \\
\hline & & Price-Standardized & $\$ 27,130$ & $\$ 29,915$ & $\$ 32,337$ & $\$ 35,341$ & $\$ 46,942$ & $\$ 19,812(73 \%)$ \\
\hline & & Price Standardized + Casemix Adjusted & $\$ 26,617$ & $\$ 29,722$ & $\$ 32,083$ & $\$ 34,927$ & $\$ 46,784$ & $\$ 20,168(76 \%)$ \\
\hline & \multirow[t]{3}{*}{90 day bundle } & Actual & $\$ 26,566$ & $\$ 30,128$ & $\$ 32,952$ & $\$ 36,573$ & $\$ 50,734$ & $\$ 24,167(91 \%)$ \\
\hline & & Price-Standardized & $\$ 27,955$ & $\$ 30,750$ & $\$ 33,237$ & $\$ 36,139$ & $\$ 47,640$ & $\$ 19,685(70 \%)$ \\
\hline & & Price Standardized + Casemix Adjusted & $\$ 27,410$ & $\$ 30,661$ & $\$ 33,063$ & $\$ 35,894$ & $\$ 47,565$ & $\$ 20,156(74 \%)$ \\
\hline & \multirow[t]{3}{*}{180 day bundle } & Actual & $\$ 28,737$ & $\$ 32,614$ & $\$ 35,553$ & $\$ 39,436$ & $\$ 54,443$ & $\$ 25,705(89 \%)$ \\
\hline & & Price-Standardized & $\$ 30,216$ & $\$ 33,420$ & $\$ 35,870$ & $\$ 38,995$ & $\$ 50,706$ & $\$ 20,490(68 \%)$ \\
\hline & & Price Standardized + Casemix Adjusted & $\$ 29,625$ & $\$ 33,143$ & $\$ 35,622$ & $\$ 38,317$ & $\$ 50,045$ & $\$ 20,420(69 \%)$ \\
\hline
\end{tabular}

*Difference reflects the variation between highest and lowest quintiles, shown as a dollar value and as a percentage of the lowest quintile value

payments for various operations (including spine surgery) with specific health-systems and providers [27]. Early data from these programs have shown reduced cost, streamlined care, and presented opportunities for "hardwired" quality improvement metrics. Some commercial insurers are also beginning to design and implement bundled payment model for their beneficiaries [28]. While episode of care based bundled payments have been implemented in some specific markets, our study shows the potential impact on cost variation for spine surgery if bundled payments were implemented on a national level.

Our findings of high variation and low post-acute care spending are consistent with prior studies of episode of care-based bundles in working age adults. A recent study examining spine surgery in working age adults with commercial insurance also found significant cost variation within and between MS-DRGs, but little difference in spending over the duration of 30-, 60-, and 90-day simulated bundles [29]. The variation in cost within MS-DRGs

Table 2 TRICARE price standardized and case mix adjusted payments by payment bucket for simulated 90-day episodes of care after cervical and non-cervical spinal fusion

\begin{tabular}{|c|c|c|c|c|c|c|c|}
\hline \multirow[t]{2}{*}{ Simulated Bundle } & \multirow[t]{2}{*}{ Payment Bucket } & \multicolumn{5}{|l|}{ Quintile } & \multirow[t]{2}{*}{ Difference* $^{*}$} \\
\hline & & 1 & 2 & 3 & 4 & 5 & \\
\hline \multirow[t]{4}{*}{ Cervical 90-day Episode of Care } & Index Hospitalization & $\$ 11,033$ & $\$ 11,673$ & $\$ 12,411$ & $\$ 13,670$ & $\$ 19,960$ & $\$ 8927$ \\
\hline & Readmissions & $\$ 0$ & $\$ 0$ & $\$ 8912$ & $\$ 9786$ & $\$ 11,522$ & $\$ 11,522$ \\
\hline & Hospital Professional Fees & $\$ 5027$ & $\$ 5752$ & $\$ 6274$ & $\$ 6898$ & $\$ 8056$ & $\$ 3029$ \\
\hline & Post-acute Care & $\$ 399$ & $\$ 571$ & $\$ 702$ & $\$ 959$ & $\$ 2070$ & $\$ 1672$ \\
\hline \multirow[t]{4}{*}{ Non-Cervical 90-day Episode of Care } & Index Hospitalization & $\$ 18,565$ & $\$ 21,372$ & $\$ 22,772$ & $\$ 25,749$ & $\$ 36,844$ & $\$ 18,278$ \\
\hline & Readmissions & $\$ 0$ & $\$ 7373$ & $\$ 8618$ & $\$ 10,120$ & $\$ 13,933$ & $\$ 13,933$ \\
\hline & Physician Fees & $\$ 6435$ & $\$ 7327$ & $\$ 7797$ & $\$ 8291$ & $\$ 9538$ & $\$ 3103$ \\
\hline & Post-acute Care & $\$ 557$ & $\$ 851$ & $\$ 1153$ & $\$ 1540$ & $\$ 2985$ & $\$ 2427$ \\
\hline
\end{tabular}

*Difference reflects the variation between highest and lowest quintiles 
may result from considerable differences previously demonstrated in both the underlying pathology and procedural complexity within MS-DRGs [30]. Non-cervical spinal fusions represent a more heterogenous mix of surgical approaches and complexity than do those of the cervical spine, which likely contributes to the higher variation seen in index admission costs. However, our findings vary considerably from studies of bundle payments in Medicare, in which post-acute care spending is a considerable driver of both total costs and variation in costs [31, 32]. This is consistent with prior research showing the likelihood of discharge to an inpatient rehabilitation center or skilled nursing facility significantly increases for older patients [33].

Our results show that there is wide variation in the readmission costs among patients and only a small number of patients underwent reoperation within 6 months of their index procedure. Prior studies have shown low overall rates of 30-day readmissions (5\%) in spine surgery patients, with the majority being related to the index initial surgery, such as wound complications [34, 35]. Working age adults are generally healthier than the older adult Medicare population, which may account for relatively flat spending over time, as they are less likely to accrue medical costs due to unrelated conditions. While rates of reoperation and readmission are already low in this population, implementation of bundles has the ability to change behavior and care practices in ways that are not accounted for by our simulated bundles. When United Healthcare implemented its "Spine and Joint Solution," a bundled payment for knee, hip, and spine surgeries, they found a $3.4 \%$ decrease in complications and a $10 \%$ decrease in readmissions for spine surgeries [28]. Similarly, other studies have shown that after implementation of bundled payments by Medicare, discharge to post-acute care also decreased $[36,37]$.

\section{Limitations}

First, as this study utilizes claims data, it may not fully capture the complete premorbid state of the patient, potentially affecting our adjustments for case mix. Similarly, patients may pay for some services out-of-pocket or in ways not captured by claims data, though it is unlikely that these expenses contribute greatly to overall costs or variation as patients in our study have a consistent insurance product. It is also unlikely for patients to pay for elements that drive costs (such as inpatient hospitalizations and long-term care) out of pocket. We also excluded patients with evidence of other insurance coverage, such as Medicare. Due to the constraints of our data use agreement, we report our results at the HRR level rather than the hospital/institution level, though facility level work presents an opportunity for future work. While MS-DRGs are a standard grouping system for conditions and procedures and are currently used for reimbursement purposes, there is varying heterogeneity within groups that limits comparisons between MS-DRGs. In this study, we create a case mix adjustment in an attempt to control for pre-operative patient characteristics, however the optimal way of risk adjusting that best considers the severity of condition, procedural difficulty, as well as comorbidities for spine surgery remains has not yet been established [38]. Additionally, our study utilizes ICD-9-CM coding, which may limit the direct applicability of our findings given the change to ICD-10-CM coding in the US, if care patterns have changed.

\section{Conclusions and implications}

The large variation in the cost of care for spinal surgery in working age adults indicates that there is a clear opportunity to implement a value-based payment model for these types of procedures. Unlike in studies of older adults, postdischarge spending following spine surgery among working age adults is low and does not increase substantially over the 6-months post discharge period. This suggests that increasing the episode length beyond to current standard of 90-days would do little to better control the variation in costs related to spine surgery among working age adults.

\section{Supplementary Information}

The online version contains supplementary material available at https://doi. org/10.1186/s12913-021-06112-0.

Additional file 1. Episode Selection.

\section{Abbreviations}

HRR: Hospital Referral Regions; ICD-9-CM: International Classification of Diseases ICD, Ninth Revision, Clinical Modification; MS-DRG: Medicare Severity - Diagnosis Related Group; US: United States

Acknowledgements

Not applicable.

\section{Disclaimer}

The contents, views or opinions expressed in this presentation are those of the author(s) and do not necessarily reflect official policy or position of Uniformed Services University of the Health Sciences, the Department of Defense, or Departments of the Army, Navy, or Air Force, or the Henry M. Jackson Foundation for the Advancement of Military Medicine, Inc. Mention of trade names, commercial products, or organizations does not imply endorsement by the U.S. Government.

\section{Authors' contributions}

MKD, CM, MDH, and JSW made substantial contributions to the conception or design of the study. TPK acquired the data. AM performed the analysis of the data. MKD, AM, CM, MDH, WW-J, and JSW contributed toward the interpretation of the data. MKD, CM, AM, and JSW drafted the manuscript. ZC,

TPK, and JSW provided overall study supervision. All authors provided critical feedback and content to the manuscript, approved of the final manuscript, and agree to be accountable for all aspect of this work.

\section{Funding}

This study was funded through the Comparative Effectiveness and ProviderInduced Demand Collaboration (EPIC) / Low-Value Care in the National 
Capital Region Project, by the United States Defense Health Agency, Grant \# HU0001-11-1-0023. The funding agency played no role in the design, analysis, or interpretation of findings.

\section{Availability of data and materials}

The data that support the findings of this study are available from the United States Defense Health Agency. Restrictions apply to the availability of these data, which were used under federal Data User Agreements for the current study, and so are not publicly available.

\section{Ethics approval and consent to participate}

Due the secondary analysis of existing, de-identified data, this study was deemed exempt from human subjects review by the Institutional Review Board of the Uniformed Services University of the Health Sciences. Because of these conditions, written consent to participate, including by parents or guardians for children under 18 , is not applicable.

\section{Consent for publication}

Due to the secondary analysis of de-identified data, consent for publication is not applicable.

\section{Competing interests}

The authors declare that we have no competing interests.

\section{Author details}

${ }^{1}$ Center for Surgery and Public Health, Harvard Medical School, Harvard T. H. Chan School of Public Health, Department of Surgery, Brigham and Women's Hospital, 1620 Tremont Street, 1 Brigham Circle, Boston, MA 02120, USA. ${ }^{2}$ Department of Health Policy and Management, Harvard T. H. Chan School of Public Health, 677 Huntington Ave, Boston, MA 02115, USA. ${ }^{3}$ Research and Communication Unit for Musculoskeletal Health (FORMI), Oslo University Hospital, PO Box 4950, Nydalen, 0424 Oslo, Norway. ${ }^{4}$ Commonwealth Fund Harkness Fellowship, 1 East 75th Street, New York, NY 10021, USA. ${ }^{5}$ Department of Orthopaedics, Walter Reed National Military Medical Center, 8901 Wisconsin Ave, Bethesda, MD 20814, USA. ${ }^{6}$ F. Edward Hébert School of Medicine, Uniformed Services University of the Health Sciences, 4301 Jones Bridge Road, Bethesda, MD 20184, USA.

Received: 10 August 2020 Accepted: 24 January 2021

\section{Published online: 02 February 2021}

\section{References}

1. Fisher ES, Bynum JP, Skinner JS. Slowing the growth of health care costs lessons from regional variation. N Engl J Med. 2009;360:849-52.

2. Berwick DM, Hackbarth AD. Eliminating waste in US health care. J Am Med Assoc. 2012:307:1513-6.

3. Porter ME. A strategy for health care reform - toward a value-based system. N Engl J Med. 2009:361:109-12. https://doi.org/10.1056/ NEJMp0904131.

4. Porter ME, Kaplan RS. How to pay for health care. Harv Bus Rev. 2016;1: 88-100 https://hbr.org/2016/07/how-to-pay-for-health-care. Accessed 3 Mar 2020.

5. CMS Innovation Center. Bundled Payments for Care Improvement (BPCI) Initiative: General Information. https://innovation.cms.gov/innovationmodels/bundled-payments. Accessed 1 Apr 2020.

6. Birkmeyer JD, Gust C, Baser O, Dimick JB, Sutherland JM, Skinner JS. Medicare payments for common inpatient procedures: implications for episode-based payment bundling. Health Serv Res. 2010;45(6 PART 1): 1783-95.

7. Miller DC, Gust C, Dimick JB, Birkmeyer N, Skinner J, Birkmeyer JD. Large variations in medicare payments for surgery highlight savings potential from bundled payment programs. Health Aff. 2011;30:2107-15.

8. Cutler DM, Ghosh K. The potential for cost savings through bundled episode payments. N Engl J Med. 2012;366:1075-7.

9. Gani F, Makary MA, Wick EC, Efron JE, Fang SH, Safar B, et al. Bundled payments for surgical colectomy among medicare enrollees: potential savings vs the need for further reform. JAMA Surg. 2016;151:e160202. https://doi.org/10.1001/jamasurg.2016.0202.

10. Agarwal R, Liao JM, Gupta A, Navathe AS. The impact of bundled payment on health care spending, utilization, and quality: a systematic review. Health Aff. 2020;39:50-7.
11. Navathe AS, Troxel AB, Liao JM, Nan N, Zhu J, Zhong W, et al. Cost of joint replacement using bundled payment models. JAMA Intern Med. 2017;177: 214-22.

12. Navathe AS, Emanuel EJ, Venkataramani AS, Huang Q, Gupta A, Dinh CT, et al. Spending and quality after three years of Medicare's voluntary bundled payment for joint replacement surgery. Health Aff. 2020;39:58-66.

13. Dummit LA, Kahvecioglu D, Marrufo G, Rajkumar R, Marshall J, Tan E, et al. Association between hospital participation in a medicare bundled payment initiative and payments and quality outcomes for lower extremity joint replacement episodes. J Am Med Assoc. 2016;316:1267-78.

14. Dietz N, Sharma M, Alhourani A, Ugiliweneza B, Wang D, Nuño MA, et al. Bundled payment models in spine surgery: current challenges and opportunities, a systematic review. World Neurosurg. 2019;123:177-83.

15. Wynn-Jones W, Koehlmoos TP, Tompkins C, Navathe A, Lipsitz S, Kwon NK, et al. Variation in expenditure for common, high cost surgical procedures in a working age population: implications for reimbursement reform. BMC Health Serv Res. 2019;19:877. https://doi.org/10.1186/s12913-019-4729-2.

16. Martin Bl, Deyo RA, Mirza SK, Turner JA, Comstock BA, Hollingworth W, et al. Expenditures and health status among adults with back and neck problems. J Am Med Assoc. 2008;299:656-64.

17. Rajaee SS, Kanim LEA, Bae HW. National trends in revision spinal fusion in the USA. Bone Joint J. 2014;96-B:807-16. https://doi.org/10.1302/0301-620X. 96B6.31149.

18. Passias PG, Jalai CM, Worley N, Vira S, Marascalchi B, McClelland S, et al. Adult spinal deformity: National Trends in the presentation, treatment, and perioperative outcomes from 2003 to 2010. Spine Deform. 2017;5:342-50.

19. Passias PG, Horn SR, Liu T, Segreto FA, Bortz CA, Bendo JA. Bundled payments in spine surgery. Semin Spine Surg. 2019;31:3-6.

20. Schoenfeld AJ, Kaji AH, Haider AH. Practical guide to surgical data sets: military health system Tricare encounter data. JAMA Surg. 2018;153:679. https://doi.org/10.1001/jamasurg.2018.0480.

21. Gimbel RW, Pangaro L, Barbour G. America's "undiscovered" laboratory for health services research. Med Care. 2010;48:751-6. https://doi.org/10.2307/ 25701531.

22. Zogg CK, Jiang W, Chaudhary MA, Scott JW, Shah AA, Lipsitz SR, et al. Racial disparities in emergency general surgery: do differences in outcomes persist among universally insured military patients? J Trauma Acute Care SurgLippincott Williams and Wilkins. 2016;80:764-77.

23. Schoenfeld AJ, Jiang W, Harris MB, Cooper Z, Koehlmoos T, Learn PA, et al. Association between race and postoperative outcomes in a universally insured population versus patients in the state of California. Ann Surg. 2017; 266:267-73.

24. Gottlieb D, Zhou W, Song Y, Gilman Andrews K, Skinner J, Sutherland J. A standardized method for adjusting Medicare expenditures for regional differences in prices; 2010. http://www.intensity.dartmouth.edu/. Accessed 29 Dec 2019

25. Gottlieb DJ, Zhou W, Song Y, Andrews KG, Skinner JS, Sutherland JM. Prices don't drive regional Medicare spending variations. Health Aff. 2010;29:537-43.

26. Adesoye T, Kimsey LG, Lipsitz SR, Nguyen LL, Goodney P, Olaiya S, et al. Geographic variation in Medicare and the military healthcare system. Am J Manag Care. 2017;23:e259-64.

27. Slotkin JR, Ross OA, Coleman MR, Ryu J. Why GE, Boeing, Lowe's, and Walmart are directly buying health Care for Employees. Harv Bus Rev. 2017; https://hbr.org/2017/06/why-ge-boeing-lowes-and-walmart-are-directlybuying-health-care-for-employees. Accessed 14 Apr 2020.

28. United Healthcare's Value-Based Care Program for Knee, Hip and Spine Procedures Demonstrates Improved Health Outcomes and Reduced Costs. 2018. https://newsroom.uhc.com/news-releases/UnitedHealthcare-ValueBased-Program-For-Joint-and-Spine-Demonstrates-Improved-HealthOutcomes-and-Reduced-Costs.html. Accessed 27 Mar 2020.

29. Ugiliweneza B, Kong M, Nosova K, Huang KT, Babu R, Lad SP, et al. Spinal surgery: variations in health care costs and implications for episode-based bundled payments. Spine (Phila Pa 1976). 2014;39:1235-42.

30. Malik AT, Phillips FM, Yu E, Khan SN. Are current DRG-based bundled payment models for lumbar fusions risk-adjusting adequately? An analysis of Medicare beneficiaries. Spine J. 2020;20:32-40. https://doi.org/10.1016/j. spinee.2019.04.024.

31. Mechanic R, Tompkins C. Lessons learned preparing for medicare bundled payments. N Engl J Med. 2012;367:1873-5. https://doi.org/10.1056/ NEJMp1210823. 
32. Newhouse JP, Garber AM. Geographic variation in Medicare services. N Engl J Med. 2013;368:1465-8.

33. Abt NB, McCutcheon BA, Kerezoudis P, Murphy M, Rinaldo L, Fogelson J, et al. Discharge to a rehabilitation facility is associated with decreased 30day readmission in elective spinal surgery. J Clin Neurosci. 2017;36:37-42.

34. Bernatz JT, Anderson PA. Thirty-day readmission rates in spine surgery: systematic review and meta-analysis. Neurosurg Focus. 2015;39:E7.

35. Piper K, DeAndrea-Lazarus I, Algattas H, Kimmell KT, Towner J, Li YM, et al. Risk factors associated with readmission and reoperation in patients undergoing spine surgery. World Neurosurg. 2018;110:e627-35.

36. Jubelt LE, Goldfeld KS, Chung WY, Blecker SB, Horwitz LI. Changes in discharge location and readmission rates under medicare bundled payment. JAMA Intern Med. 2016;176:115-7.

37. Joynt Maddox KE, Orav EJ, Zheng J, Epstein AM. Post-acute care after joint replacement in Medicare's bundled payments for care improvement initiative. J Am Geriatr Soc. 2019;67:1027-35. https://doi.org/10.1111/jgs.15803.

38. Tsai TC, Miller DC. Bundling payments for episodes of surgical care. JAMA Surg. 2015;150:905-6.

\section{Publisher's Note}

Springer Nature remains neutral with regard to jurisdictional claims in published maps and institutional affiliations.

Ready to submit your research? Choose BMC and benefit from:

- fast, convenient online submission

- thorough peer review by experienced researchers in your field

- rapid publication on acceptance

- support for research data, including large and complex data types

- gold Open Access which fosters wider collaboration and increased citations

- maximum visibility for your research: over $100 \mathrm{M}$ website views per year

At BMC, research is always in progress.

Learn more biomedcentral.com/submissions 